\title{
Association of HLA Alleles and HLA Haplotypes with Psoriasis, Psoriatic Arthritis and Disease Severity in a Miscegenated Population
}

\author{
Flavia de Freire Cassia (iD \\ Juliana Fernandes Cardoso (iD ${ }^{2}$ \\ Luiz Cristovao Porto (iD ${ }^{3}$ \\ Marcia Ramos-e-Silva (iD) \\ Sueli Carneiro (iD ${ }^{4}$ \\ 'Sector of Dermatology, Post-Graduation \\ Course in Dermatology, University \\ Hospital and School of Medicine, Federal \\ University of Rio de Janeiro, Rio de \\ Janeiro, Brazil; ${ }^{2}$ Histocompatibility \\ Section, Special Techniques Laboratory, \\ Albert Einstein Israelite Hospital- HIAE, \\ São Paulo, Brazil; ${ }^{3}$ Histocompatibility and \\ Cryopreservation Laboratory, Rio de \\ Janeiro State University, Rio de Janeiro, \\ Brazil; ${ }^{4}$ Sector of Dermatology, \\ University Hospital and School of Medical \\ Sciences, State University of Rio de \\ Janeiro, Rio de Janeiro, Brazil
}

Background: The study of HLA classes I and II in Brazilian psoriasis patients may contribute to a better understanding of their association with the disease.

Objective: To describe HLA classes I and II of Brazilian patients with psoriasis, with or without arthritis, compare them to controls and correlate HLA markers with epidemiological and evolutional aspects of psoriasis.

Methods: A total of 55 patients with more than 5 years of psoriasis, with or without arthritis, answered a questionnaire on ethnic background and disease severity. A total of 134 bone marrow donors were controls. HLA class I and II genotyping was determined by PCR-SSP.

Results: Mean age was 42.4 years; 23 women and 32 men. HLA-B*57 was present in $23.6 \%$ patients and in $7.5 \%$ controls $(\mathrm{p}=0.00200, \mathrm{OR}=3.8381$ ), and HLA-C*06 in $29.1 \%$ patients and in $16.4 \%$ controls $(\mathrm{p}=0.04832, \mathrm{OR}=2.0886)$. HLA-B*57 and HLA-C*18 were significantly present in patients with arthritis $(\mathrm{p}=0.00104, \mathrm{OR}=6.6769$ and $\mathrm{p}=0.00269, \mathrm{OR}=16.50$, respectively). HLA-B*57 was significantly present in patients with history of erythroderma $(\mathrm{p}=0.00548, \mathrm{OR}=5.1059)$, as was HLA-C*06 $(\mathrm{p}=0.02158, \mathrm{OR}=3.0545)$. HLA-B*57 was also frequent in patients with history of hospital internment due to psoriasis $(p=0.00094$, $\mathrm{OR}=7.8909)$ and in the ones with history of systemic treatment for psoriasis $(p=0.00011$, $\mathrm{OR}=5.3733$ ). Haplotype HLA-A*02 B*57 C*06 DRB1*07DQB $1 * 03$ was the most common among the patients $(\mathrm{p}=0.00069, \mathrm{OR}=3.528)$.

Conclusion: HLA-B*57 and HLA-C*06 were significantly increased in the patients indicating risk for psoriasis. HLA-B*57 remained high in patients with history of erythroderma, hospital internment, systemic treatment, and psoriatic arthritis, showing association with disease severity. HLA-C*18 was significantly high only in patients with psoriatic arthritis. HLA-B*57 and HLA-C*06 and haplotype HLA-A*02B*57Cw*06DRB1*07 DQB1*03 seen in this study were already described before, associated with psoriasis. HLA-Cw*18 was not described in other populations in association with psoriasis.

Keywords: psoriasis, psoriatic arthritis, HLA, population study

\section{Introduction}

Psoriasis is a chronic inflammatory disease mediated by $\mathrm{T}$ lymphocytes, with participation of dendritic cells. Genetic and environmental factors contribute or are required for the development of overt disease. The lesions are characterized by erythema and desquamation, configuring different clinical forms, from sharply delimited plaques to diffuse erythroderma. Up to $30 \%$ of patients may also have joint involvement, which may result, if untreated, in erosive disease and incapacity.
Correspondence: Flavia de Freire Cassia Sector of Dermatology, Post-Graduation Course in Dermatology, University Hospital and School of Medicine, Federal University of Rio de Janeiro, Rua Jardim Botanico, 700 /416, Rio de Janeiro, 2246I. 000, Brazil

Tel +55 21999640406

Email flaviafcassia@gmail.com 
It is considered a prevalent disease, affecting $2 \%$ of the population in Western countries.

Many of the psoriasis-associated genes seem to support the hypothesis that a particular immunologic disposition increases the risk of developing psoriasis. PSORS1 is the most associated gene. This locus maps to chromosome 6 21.3, comprising many different class I antigens associated with disease expression. HLA-C has been repeatedly described as the PSORS1 gene, and HLA- $\mathrm{Cw}^{*} 06: 02$ as the susceptibility allele. Tumor necrosis factor promoter polymorphism $\mathrm{TNF}^{*}-857$ is a risk allele for psoriatic arthritis independent of the PSORS1 locus. ${ }^{1}$

The activation of $T$ cells in conjunction with mature antigen presenting cells is a multi-step process, which requires the stimulation of $\mathrm{T}$ cell receptors and many accessory signals. The initial interaction that triggers $\mathrm{T}$ cell activation is the recognition of the peptide antigen that is bound to the HLA class I molecule (for intracellular antigens) or HLA class II (for extracellular antigens) in the antigen presenting cells. The study of the HLA molecules associated with psoriasis may not only point to disease susceptibility genes, but also to clarify some aspects of its pathogenesis and therefore potential targets to therapy. HLA molecules may bind to psoriasis related antigens through the clefts they form, determining the size and charge of the peptide antigen. ${ }^{2-4}$

The association of HLA molecules with the occurrence of psoriasis vulgaris and psoriatic arthritis is widely described in the literature. ${ }^{5-15}$ Studies in populations of different ethnic origins show the increased frequency of different HLA specificities and haplotypes in patients with psoriasis when compared to control groups. ${ }^{8,16-18}$ Often, this frequency is even higher in patients with early-onset psoriasis and familial history of the disease. ${ }^{19-22}$

The miscegenation of Caucasians, Africans and native Indians is the main feature of the Brazilian population, which has in the "mestizos" its greatest representation. The study of class I and II HLA in Brazilian psoriasis patients contributes to a better understanding their association with the disease, especially when compared to other populations of different ethnic origins. The study of class I and II HLA genes of Brazilian psoriasis vulgaris patients, with or without arthritis, may contribute with new information regarding immunopathogenesis and susceptibility to disease in this group of patients.

The aim of this study is to determine allelic groups and haplotypes of human leukocyte antigens (HLA) in a psoriasis group of patients characterized by miscegenation and correlate them with disease severity, through evolutional aspects seen in our patients.

\section{Methods}

Fifty-five patients with clinical and/or histopathological diagnosis of psoriasis vulgaris, with at least 5 years of disease duration, and with or without arthritis, were included in the study. They answered a questionnaire on ethnic background, family history and duration of disease. They were clinically evaluated in respect to distribution and morphology of skin lesions, joint involvement and disease activity and were submitted to laboratorial tests. The criteria used to assess the severity of the disease (unfavorable evolution) were episodes of hospitalization, the use of systemic treatment, episodes of erythroderma and/or presence of arthritis, as many patients were under treatment when were enrolled. PASI (Psoriasis Activity and Severity Index) was not used as a severity parameter for the same reason. Patients enrolled have had psoriasis for at least five years (as an inclusion criteria) and PASI of 10 or more sometime during follow up, configuring moderate to severe psoriasis. Psoriasis was classified as type I when the onset of the disease occurred until 30 years-old and type II after 30 years-old.

Cases and controls were matched for age, sex and ethnic origin. One hundred and thirty-four healthy bone marrow donors served as controls after informed consent. They answered the same questionnaire on ethnic background. Controls had no family history of psoriasis or diseases related to HLA-C. Allelic typing of class I and II genes were determined by PCR-SSP. Differences between the two groups were evaluated through Chisquare or Fisher exact tests.

\section{HLA Typing}

Peripheral blood $(15 \mathrm{~mL})$ was collected in sterile tubes containing anticoagulant. Genomic DNA from both psoriasis patients and controls was isolated from leukocytes using a GFX Genomic Blood DNA Purification (Amersham Biosciences, LTD, UK) kit. HLA -A -B -C -DR -DQ alleles were determined using microplates containing the sequence specific primers (PCR/SSP). PCR amplification was carried out in 30 cycles that included denaturation at $96^{\circ} \mathrm{C}$ for $10 \mathrm{sec}$, annealing at $63^{\circ} \mathrm{C}$ for 60 sec and extension at $72^{\circ} \mathrm{C}$ for $30 \mathrm{sec}$, as fabricant protocol (One Lambda, INC, CA, USA). PCR products were analyzed by electrophoresis in ethidium bromide-stained $2 \%$ agarose gel. Presence of the specific PCR products were 
interpreted by analysis of positive bands using worksheets and an interpretation software (DNA LMT - One Lambda, INC, CA, USA).

\section{Results}

\section{Patients}

Fifty-five patients with psoriasis vulgaris and 134 controls were included in the study. The mean age of patients was 42.4 years (SD 10.5262), while the median was 43.0 years (from 19.0 to 63.0 years). The mean age of the controls was 40.5 years (SD 8.5423) and median 41.5 years $(22.0$ to 59.0 years). There were $23(41.8 \%)$ female and 32 $(58.2 \%)$ male patients and in the control group, 65 $(48.5 \%)$ were female and $69(51.5 \%)$ were male (Table 1$)$.

Seventeen $(30.9 \%)$ patients had a positive family history for psoriasis. Eighteen $(32.7 \%)$ had been hospitalized because of psoriasis, $24(43.6 \%)$ have had one or more episodes of erythroderma (erythrodermic psoriasis) and 43 $(78.2 \%)$ have used a systemic treatment for the disease. Of the 43 with systemic treatment history, 19 have arthritis and 23 had a history of erythroderma. Ten patients had a history of both erythroderma and arthritis (Table 2).

The average age of onset of the disease was 26.56 years and the mean duration of disease was 16.90 years. In $33(60.0 \%)$ patients psoriasis began before age 30 (type I psoriasis), and the mean age of onset of the disease 19.09 years. In the other $22(40.0 \%)$, it emerged from 30 years (psoriasis type II) with a mean age of onset of the disease 37.77 years. The family history of psoriasis was positive in $10(30.3 \%)$ patients with psoriasis type I and in 7 (31.8\%) patients with psoriasis type II $(\mathrm{p}=0.90517)$, as seen in Table 3 .

Psoriatic arthritis was found in 20 (36.4\%) of the patients included in the study, 11 males and 9 females. The mean duration of arthritis was 11.05 years. Of the 20 patients, $15(75 \%)$ showed involvement of peripheral (polyarthritis: 13 and oligoarthritis: 2) and 5 (25\%), axial involvement. Of these, 2 patients were diagnosed with sacroileitis and 2 with ankylosing spondylitis, only 1 had spondylitis and erosive arthritis. No patient had only distal interphalangeal arthritis.

\section{Frequency of HLA Allelic Groups}

Two allelic groups showed to be increased in the patients with psoriasis compared to controls. HLA-B*57 was present in $13(23.6 \%)$ patients and in $10(7.5 \%)$ controls $(\mathrm{p}=$ $0.00200, \mathrm{RC}=-9.39881 .56733 .8381 \mathrm{CI})$ and HLA-C*06 was present in $16(29.1 \%)$ patients and in $22(16.4 \%)$ controls $(\mathrm{p}=0.04832, \mathrm{RC}=2.0886, \mathrm{CI}=0.9965$ $-4.3773)$.

HLA-B*07 was present more often in the control group, with statistical significance: it was positive in 19 (14.2\%) controls and $2(3.6 \%)$ patients $(\mathrm{p}=0.02599, \mathrm{RC}=$ $0.2284, \mathrm{CI}=0.0513$ to 1.0164$)$.

HLA-B*57 was significantly present in the psoriatic arthritis patient group $(\mathrm{p}=0.0010493305, \mathrm{RC}=6.6769$ $\mathrm{CI}=2.1736$ to 20.5099$)$. The HLA-C*18 was also increased significantly in the group of patients with arthritis $(\mathrm{p}=0.0026978977, \mathrm{RC}=16.5000, \mathrm{CI}=2.7967$ to 97.3486). The HLA-B*51 was considered a protective allele, as it was present in $23(17.2 \%)$ controls and no

Table I Distribution of Cases and Controls (Age. Gender and Ethnics)

\begin{tabular}{|c|c|c|c|}
\hline & Psoriasis $(n=55)$ & Controls $(n=134)$ & $p$ \\
\hline $\begin{array}{l}\text { Median age (sd) } \\
\text { Mean }\end{array}$ & $\begin{array}{l}42.4 \text { years }( \pm 10.5262) \\
43.0 \text { years }(19.0-63.0)\end{array}$ & $\begin{array}{l}40.5 \text { years }( \pm 8.5423) \\
41.5 \text { years }(22.0-59.0)\end{array}$ & 0.2075 \\
\hline $\begin{array}{c}\text { Gender } \\
\text { Male } \\
\text { Female }\end{array}$ & $\begin{array}{l}32(58.2 \%) \\
23(41.8 \%)\end{array}$ & $\begin{array}{l}69(51.5 \%) \\
65(48.5 \%)\end{array}$ & 0.4036 \\
\hline $\begin{array}{l}\text { Ethnics } \\
\text { White } \\
\text { Mestizo/White } \\
\text { Mestizo/Indian } \\
\text { Mestizo/Black } \\
\text { Black }\end{array}$ & $\begin{array}{l}10(18.2 \%) \\
18(32.7 \%) \\
11(20 \%) \\
7(12.7 \%) \\
9(16.4 \%)\end{array}$ & $\begin{array}{l}36(26.9 \%) \\
35(26.1 \%) \\
19(14.2 \%) \\
24(17.9 \%) \\
20(14.9 \%)\end{array}$ & 0.5028 \\
\hline
\end{tabular}

Note: Groups are comparable in relation to age. Gender and ethnics $(p>0.05)$.

Abbreviation: sd, standard deviation. 


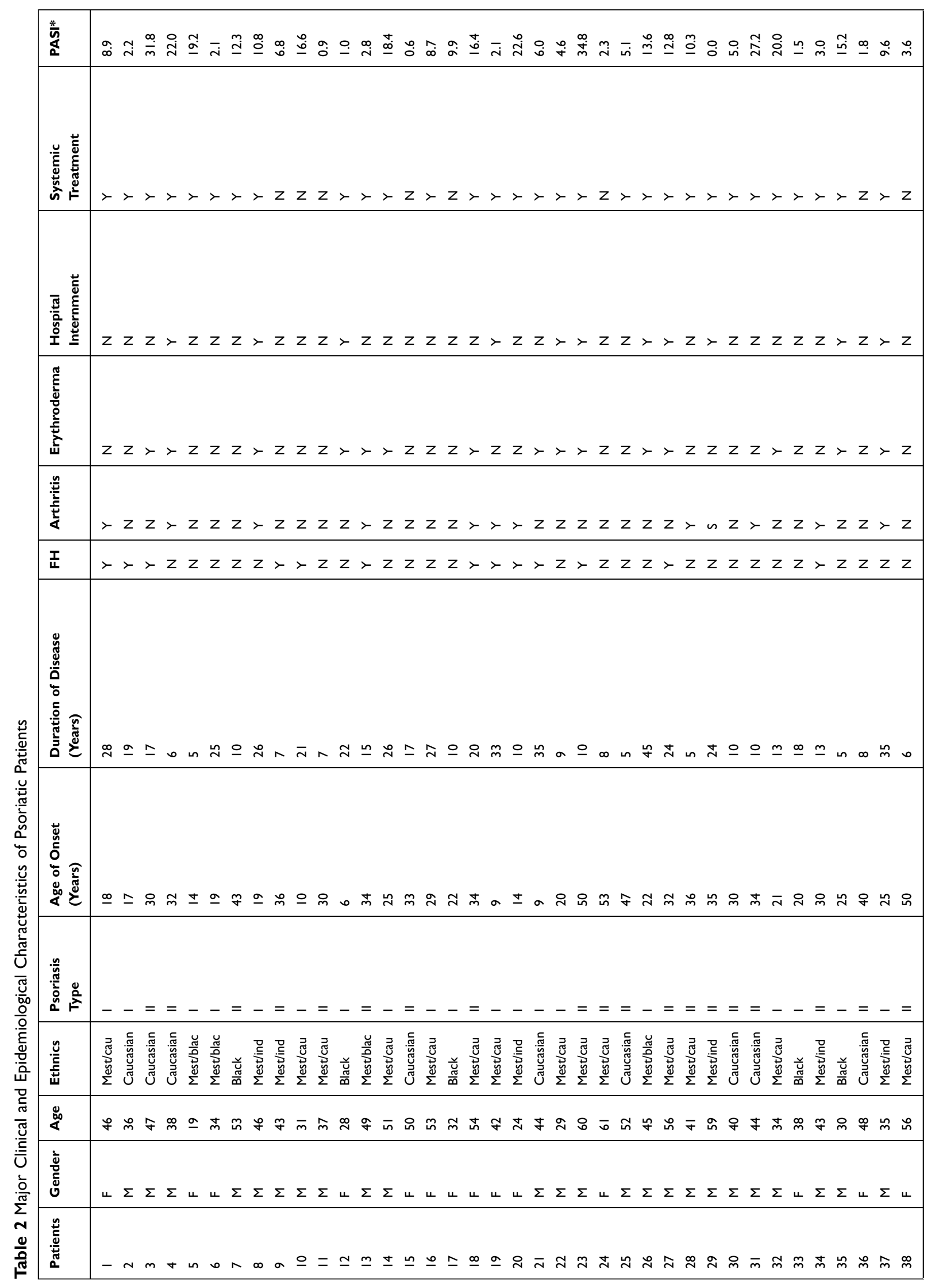




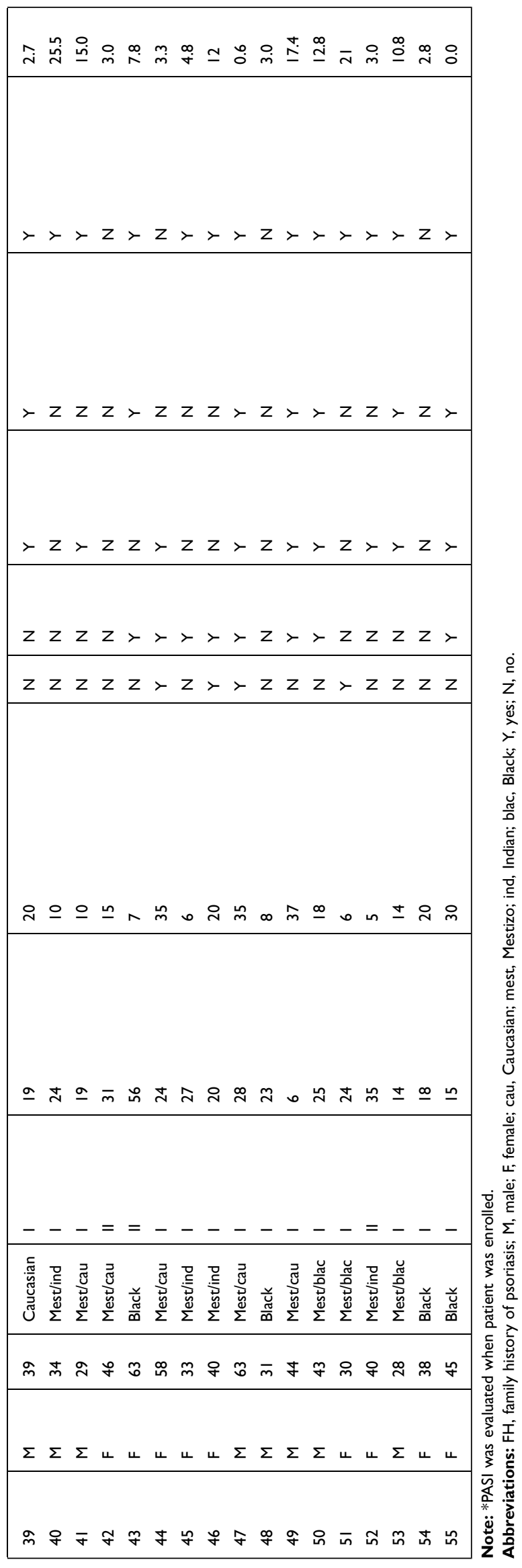

patients $(\mathrm{p}=0.0309950651, \quad \mathrm{RC}=0.0000, \mathrm{CI}=$ Undefined). Only 1 patient was positive for HLA-B*27; it is one of the five patients with axial involvement (spondylitis).

When patients were divided in relation to age of disease onset (before and after age 30), HLA-B*57 and HLA$\mathrm{C} * 06$ remained significantly present in patients with type I compared to controls $(\mathrm{p}=0.0002958858, \mathrm{RC}=5.3913$, CI $=2.0173$ to $14.4083 \mathrm{p}=0.0108075985, \mathrm{RC}=2.9091, \mathrm{CI}=$ 1.2511 to 6.7641 , respectively), both with significance greater than that seen in the group of patients when compared to controls. The allelic group HLA-DRB1*13 was present in a statistically significant way in type I psoriasis patients only $(\mathrm{p}=0.0108075985, \mathrm{RC}=2.9091, \mathrm{CI}=$ 1.2511 to 6.7641). In type II patients, allelic groups HLA-B*14 and HLA-C*08 were significantly increased when compared to controls $(\mathrm{p}=0.0039573385, \mathrm{RC}=$ 4.8980, $\mathrm{CI}=1.7485$ to 13.7203 and $\mathrm{p}=0.0134889571$, $\mathrm{RC}=4.0000, \mathrm{CI}=1.3939$ to 11.4786 , respectively). The presence of allelic groups HLA-B * 57 and HLA-C * 06 were not statistically significant in type II patients only. In patients with positive family history, there was no statistically significant allelic group.

HLA-B*57 and HLA-C*06 were seen in patients with erythrodermic psoriasis history $(\mathrm{p}=0.0054885048, \mathrm{RC}=$ $5.1059, \mathrm{CI}=1.7153-15.1990$ and $\mathrm{p}=0.0215894577, \mathrm{RC}$ $=3.0545, \mathrm{CI}=1.1880-7.8540$, respectively). The HLA-B * 57 was also increased in patients with hospital admissions for psoriasis $(\mathrm{p}=0.0009478272, \mathrm{RC}=7.8909, \mathrm{CI}=$ 2.5087-24.8200) and in those with history of using systemic treatment for the disease $(\mathrm{p}=0.0001128264, \mathrm{RC}=$ 5.3733, CI $=2.1504-13.4268$ ). The frequency of HLA-A, B, C, DRB1 and DQB1 allelic groups are seen on Tables 4-8.

\section{HLA Haplotypes}

The haplotype HLA-A*02 B*57 Cw*06 DRB1*07 DQB1*03 was the most common, but was present in only $4(3.6 \%)$ patients and no controls $(\mathrm{p}=0.0069$, OR $=3.528, \mathrm{CI}=3.003$ to 4.145$)$. Two other haplotypes were present in $3(2.7 \%)$ patients and no controls $(\mathrm{p}=0.0242$, $\mathrm{HR}=3.505, \mathrm{CI}=2.986$ to 4.114$):$ HLA-A*02 $\mathrm{B}^{*} 13$ Cw*06 DRB1*07 DQB1*02 and HLA-A*02 B*14 $\mathrm{Cw}^{*} 08 \mathrm{DRB} 1 * 01 \mathrm{DQB} 1 * 5$. Nine haplotypes were found in $2(1.8 \%)$ patients and in no control $(\mathrm{p}=0.0841, \mathrm{HR}=$ 3.481, $\mathrm{CI}=2.969$ to 4.083$)$ : HLA-A*01 $\mathrm{B} * 08 \mathrm{Cw}^{*} 07$ DRB1*03 DQB1*02, HLA-A*02 B*49 Cw * 07 DRB1*04 DQB1*03, HLA-A*02 B*58 Cw*07 
Table 3 Clinical and Epidemiological Characteristics of Patients with Type I and II Psoriasis

\begin{tabular}{|l|l|l|l|l|}
\hline & Type I (n=33) & Type II (n=22) & $p$ & OD (CI) \\
\hline Mean age at disease onset -years (sd) & $19.09(6.1764)$ & $37.77(8,2285)$ & - & - \\
Mean time of duration of disease - years (sd) & $20.6363(I I .019)$ & $I I .318(5.987)$ & 0.0007 & - \\
Family history & $10(30.3 \%)$ & $7(31.8 \%)$ & 0.90604 & $1.0733(0.3350-3.4394)$ \\
Arthritis & $12(36.3 \%)$ & $8(36.3 \%)$ & 1.0000 & $1.0000(0.3258-3.0693)$ \\
Hospital internment & $13(39.3 \%)$ & $5(22.7 \%)$ & 0.20009 & $0.4525(0.1339-1.5286)$ \\
Erythroderma & $17(51.5 \%)$ & $7(31.8 \%)$ & 0.15277 & $0.4392(0.1423-1.3561)$ \\
Systemic treatment & $28(84.8 \%)$ & $15(68.1 \%)$ & 0.14629 & $0.3827(0.1035-1.4151)$ \\
\hline
\end{tabular}

Note: Both groups were similar $(p>0.05)$ in relation to family history and criteria used to evaluate disease severity.

Abbreviations: $\mathrm{OD}$, odds ratio; $\mathrm{Cl}$, confidence interval.

DRB1*03 DQB1*02, HLA-A*03 B*14 Cw*08 DRB1*03 $\mathrm{DQB} 1 * 02$. HLA-A*11 B*55 Cw*03 DRB1*14 DQB1*02, HLA-A*24 B*35 Cw*04 DRB1*11 DQB1*03, HLA$\mathrm{A} * 34 \mathrm{~B} * 14 \mathrm{CW} * 08 \mathrm{DRB} 1 * 11$ DQB1*06, HLA-A*68 $\mathrm{B} * 14 \mathrm{Cw}^{*} 08 \mathrm{DRB} 1 * 01 \mathrm{DQB} 1 * 05$ and HLA-A*74 B*35 $\mathrm{CW}^{*} 04 \mathrm{DRB} 1 * 03 \mathrm{DQB} 1 * 04$.

\section{Discussion}

In this study, two allelic groups were more frequent in the group of patients with psoriasis compared to controls: the HLA-B*57 and HLA-C*06. Both were present even more in patients with psoriasis type I. In all studies in which the
HLA class I was typified, HLA-Cw6 or C*06 was present with a statistically significant frequency in psoriasis patients. ${ }^{10,17,21-27}$ In Germany, Thailand, China, Sweden and Croatia HLA-Cw6 was a marker only in psoriasis type I. $^{8,20,22,25-28}$ Oostveen et al found an association of HLA$\mathrm{Cw} 06$ with paediatric onset of psoriasis, but not with family history of psoriasis in a cohort of patients. ${ }^{29}$

The HLA-B * 57 also was increased in Chinese patients with psoriasis vulgaris ${ }^{27}$ and was seen in type I psoriasis patients in Germany ${ }^{20}$ and Thailand. ${ }^{30,31}$ Gonzaga et $\mathrm{al}^{23}$ used serological methods to study 22 Brazilian patients with psoriasis vulgaris and showed an increased frequency

Table 4 Frequency of HLA-A Allelic Groups in Patients and Controls

\begin{tabular}{|c|c|c|c|c|}
\hline HLA-A* & $\begin{array}{l}\text { Psoriasis } \\
n=1 / 0\end{array}$ & $\begin{array}{l}\text { Controls } \\
n=268\end{array}$ & $p$ & OD (CI) \\
\hline 01 & $10(18.2 \%)$ & $22(16.4 \%)$ & 0.76898 & $1.1313(0.4964-2.5781)$ \\
\hline 02 & 27 (49.1\%) & $56(4 I .8 \%)$ & 0.35834 & I.343। (0.7|5।-2.5227) \\
\hline 03 & 9 (16.4\%) & $23(17.2 \%)$ & 0.89395 & $0.9442(0.406 \mathrm{I}-2.1955)$ \\
\hline II & $5(9.1 \%)$ & $16(11.9 \%)$ & 0.57127 & $0.737(0.2562-2.1229)$ \\
\hline 23 & 7 (I2.7\%) & 20 (I4.9\%) & 0.69486 & $0.8313(0.3298-2.0952)$ \\
\hline 24 & $8(14.5 \%)$ & $22(16.4 \%)$ & 0.74898 & $0.8665(0.3602-2.0849)$ \\
\hline 25 & $3(5.5 \%)$ & $6(4.5 \%)$ & 0.51538 & $1.2308(0.2966-5.1067)$ \\
\hline 26 & $2(3.6 \%)$ & $10(7.5 \%)$ & 0.26665 & $0.4679(0.099 \mathrm{I}-2.2088)$ \\
\hline 29 & $\mathrm{I}(\mathrm{I} .8 \%)$ & $10(7.5 \%)$ & 0.11805 & $0.2296(0.0287-1.8387)$ \\
\hline 30 & $5(9.1 \%)$ & $15(11.2 \%)$ & 0.66942 & $0.7933(0.2736-2.3006)$ \\
\hline 31 & $4(7.3 \%)$ & $7(5.2 \%)$ & 0.40329 & $1.4230(0.3993-5.0707)$ \\
\hline 32 & $3(5.5 \%)$ & $10(7.5 \%)$ & 0.44464 & $07154(0.1892-2.7056)$ \\
\hline 33 & $5(9.1 \%)$ & $9(6.7 \%)$ & 0.38443 & $13,889(0.4436-4.3487)$ \\
\hline 34 & $4(7.3 \%)$ & $3(2.2 \%)$ & 0.11051 & $3.4248(0.7405-15.8407)$ \\
\hline 36 & $\mathrm{I}(\mathrm{I}, 8 \%)$ & 0 & 0.29100 & (Undefined) \\
\hline 43 & 0 & 0 & - & - \\
\hline 66 & $\mathrm{I}(\mathrm{I} .8 \%)$ & $5(3,7 \%)$ & $0.437 \mid I$ & $0.4778(0.0545-4.1864)$ \\
\hline 68 & $9(16,4 \%)$ & $14(10.4 \%)$ & 0.25849 & $1.6770(0.6793-4.1403)$ \\
\hline 69 & 0 & $\mathrm{I}(0.7 \%)$ & 0.35449 & (Undefined) \\
\hline 74 & I $(1,8 \%)$ & $7(5.2 \%)$ & 0.26769 & $0.3360(0.0404-2,7974)$ \\
\hline 80 & I (I.8\%) & 0 & 0.29100 & (Undefined) \\
\hline
\end{tabular}

Abbreviations: $\mathrm{OD}$, odds ratio; $\mathrm{Cl}$, confidence interval. 
Table 5 Frequency of HLA-B Allelic Groups in Patients and Controls

\begin{tabular}{|c|c|c|c|c|}
\hline HLA-B* & $\begin{array}{c}\text { Psoriasis } \\
n=110\end{array}$ & $\begin{array}{l}\text { Controls } \\
n=268\end{array}$ & $p$ & OR (Cl) \\
\hline 07 & $2(3.6 \%)$ & 19 (14.2\%) & 0.02599 & $0.2284(0.05$ I3 -1.0164$)$ \\
\hline 08 & $3(5.5 \%)$ & $8(6.0 \%)$ & 0.59670 & $0.9087(0.2319-3.5605)$ \\
\hline 13 & $3(5.5 \%)$ & $2(1.5 \%)$ & 0.148511 & $3.8077(0.6183-23.448)$ \\
\hline 14 & $10(18.2 \%)$ & $14(10.4 \%)$ & 0.14691 & $1.9048(0.7894-4.5962)$ \\
\hline 15 & II (20.0\%) & $22(16.4 \%)$ & $0.5557 \mid$ & I.2727 (0.5699-2.8422) \\
\hline 18 & $3(5.5 \%)$ & $14(10.4 \%)$ & 0.21286 & $0.4945(0.1363-1.7942)$ \\
\hline 27 & $\mathrm{I}(\mathrm{I} .8 \%)$ & 10 (7.5\%) & 0.06906 & $0.2296(0.0287-I .8387)$ \\
\hline 35 & II (20.0\%) & $38(28.4 \%)$ & 0.23365 & $0.6316(0.2954-1.3505)$ \\
\hline 37 & $3(5.5 \%)$ & $2(1.5 \%)$ & 0.14851 & $3.8077(0.6183-23.4484)$ \\
\hline 38 & $5(9.1 \%)$ & $6(4.5 \%)$ & $0.1846 \mathrm{I}$ & $2.1333(0.6229-7.306 I)$ \\
\hline 39 & $\mathrm{I}(\mathrm{I} .8 \%)$ & II (8.2\%) & 0.08832 & $0.207 \mid(0.026 I-I .6443)$ \\
\hline 40 & $3(5.5 \%)$ & $4(3.0 \%)$ & 0.33105 & $1.8750(0.4055-8.6689)$ \\
\hline 41 & 0 & $3(2.2 \%)$ & 0.35405 & 0 (Undefined) \\
\hline 42 & $\mathrm{I}(\mathrm{I} .8 \%)$ & $8(6.0 \%)$ & $0.2057 \mid$ & $0.2917(0.0356-2.3894)$ \\
\hline 44 & 8 (14.5\%) & $23(17.2 \%)$ & 0.65876 & $0.8215(0.3428-1.9683)$ \\
\hline 45 & $\mathrm{I}(\mathrm{I} .8 \%)$ & $2(1.5 \%)$ & 0.64594 & $1.2222(0.1085-13.7627)$ \\
\hline 47 & 0 & 0 & - & - \\
\hline 48 & 0 & I (0.7\%) & 0.70899 & 0 (Undefined) \\
\hline 49 & $5(9.1 \%)$ & $12(9.0 \%)$ & 0.58617 & $1.0167(0.3405-3.0359)$ \\
\hline 50 & $\mathrm{I}(\mathrm{I} .8 \%)$ & $6(4.5 \%)$ & 0.34437 & $0.395 I(0.0464-3.3605)$ \\
\hline 51 & $6(10.9 \%)$ & $23(17.2 \%)$ & 0.27846 & $0.5909(0.2264-1.5423)$ \\
\hline 52 & $2(3.6 \%)$ & $4(3.0 \%)$ & 0.56288 & $1.2264(0.2180-6.8985)$ \\
\hline 53 & $4(7.3 \%)$ & $6(4.5 \%)$ & 0.32377 & $1.6732(0.4532-6.1773)$ \\
\hline 54 & 0 & 0 & - & - \\
\hline 55 & $2(3.6 \%)$ & $2(1.5 \%)$ & 0.33186 & $2.4906(0.3419-18.142)$ \\
\hline 56 & 0 & I (0.7\%) & 0.70899 & 0 (Undefined) \\
\hline 57 & $13(23.6 \%)$ & $10(7.5 \%)$ & 0.00200 & $3.8381(1.5673-9.3988)$ \\
\hline 58 & $6(10.9 \%)$ & 7 (5.2\%) & 0.13937 & $2.2216(0.7 \mathrm{III}-6.9406)$ \\
\hline 59 & 0 & 0 & - & - \\
\hline 67 & 0 & 0 & - & - \\
\hline 73 & 0 & 0 & - & - \\
\hline 78 & 0 & 0 & - & - \\
\hline 81 & 0 & $2(1.5 \%)$ & 0.50157 & 0 (Undefined) \\
\hline 82 & 0 & 0 & - & - \\
\hline
\end{tabular}

Note: Bold lines highlight $p$ value $<0.05$.

Abbreviations: $\mathrm{OD}$, odds ratio; $\mathrm{Cl}$, confidence.

of HLA-B17 and Cw6. HLA-B57 and B58 correspond to the serologic HLA-B17 splits and in terms of DNA analysis, to the alleles $\mathrm{B} * 5701, \mathrm{~B} * 5702$ or $\mathrm{B} * 5801$.

Allelic groups HLA-B*14 and HLA-Cw*08 were significantly increased in psoriasis type II patients. Although in linkage disequilibrium, they have not been described in the literature as susceptibility alleles to psoriasis. HLA-Cw7 and HLA-Cw*01 were significantly increased in type II patients in Turkey and Thailand, respectively. ${ }^{17,30}$
Regarding HLA class II, the allelic group HLA-DRB1*13 was statistically significant only in type I psoriasis. Rather, Cardoso et $\mathrm{al}^{32}$ published a study with Brazilian and detected the HLA-DRB1*1302 as a protective allele, but there is no description of the ethnic origin of the group studied. Serological studies in Croatia and Turkey showed an increased frequency of HLA-DR7 in type I patients, ${ }^{8,17}$ and in both groups of Finnish patients. ${ }^{6}$ Molecular methods showed that HLA-DRB1 * 0701 was present more frequently in type I patients in Germany, ${ }^{19}$ Croatia $^{24}$ and Taiwan $^{33}$ and in all 
Table 6 Frequency of HLA-Cw Allelic Groups in Patients and Controls

\begin{tabular}{|c|c|c|c|c|}
\hline HLA-C* & $\begin{array}{l}\text { Psoriasis } \\
n=110\end{array}$ & $\begin{array}{l}\text { Controls } \\
n=268\end{array}$ & $p$ & OR (Cl) \\
\hline 이 & $3(5.5 \%)$ & 7 (5.2\%) & 0.59750 & $1.0467(0.2606-4.2044)$ \\
\hline 02 & $3(5.5 \%)$ & $19(14.2 \%)$ & 0.08936 & $0.3492(0.0990-1.2322)$ \\
\hline 03 & $9(16.4 \%)$ & $17(12.7 \%)$ & 0.50500 & $1.3465(0.5602-3.2367)$ \\
\hline 04 & $13(23.6 \%)$ & $47(35.1 \%)$ & 0.12491 & $0.5729(0.2800-1.1726)$ \\
\hline 05 & 5 (9.1\%) & $9(6.7 \%)$ & 0.38443 & $1.3889(0.4436-4.3487)$ \\
\hline 06 & $16(29.1 \%)$ & $22(16.4 \%)$ & 0.04832 & $2.0886(0.9965-4.3773)$ \\
\hline 07 & $18(32.7 \%)$ & $49(36.6 \%)$ & 0.61618 & $0.8439(0.4344-1.6393)$ \\
\hline 08 & $10(18.2 \%)$ & 14 (10.4\%) & 0.14691 & $1.9048(0.7894-4.5962)$ \\
\hline 10 & $10(18.2 \%)$ & $23(17.2 \%)$ & 0.86706 & $1.0725(0.4727-2.4332)$ \\
\hline 14 & $4(7.3 \%)$ & $5(3.7 \%)$ & 0.24593 & $2.0235(0.5224-7.8384)$ \\
\hline 15 & $3(5.5 \%)$ & $14(10.4 \%)$ & 0.21286 & $0.4945(0.1363-1.7942)$ \\
\hline 16 & $3(5.5 \%)$ & $12(9.0 \%)$ & 0.31463 & $0.5865(0.1589-2.1655)$ \\
\hline 17 & $\mathrm{I}(\mathrm{I} .8 \%)$ & $10(7.5 \%)$ & 0.11805 & $0.2296(0.0287-1.8387)$ \\
\hline 18 & $4(7.3 \%)$ & $2(1.5 \%)$ & 0.06048 & $5.1765(0.9196-29.137)$ \\
\hline
\end{tabular}

Note: Bold line highlights $p$ value $<0.05$.

Abbreviations: $\mathrm{OD}$, odds ratio; $\mathrm{Cl}$, confidence interval.

Table 7 Frequency of HLA-DRBI Allelic Groups in Patients and Controls

\begin{tabular}{|c|c|c|c|c|}
\hline $\begin{array}{l}\text { HLA- } \\
\text { DRB I* }\end{array}$ & $\begin{array}{l}\text { Psoriasis } \\
n=110\end{array}$ & $\begin{array}{l}\text { Controls } \\
n=268\end{array}$ & $p$ & OR (CI) \\
\hline 01 & $12(2 \mid .8 \%)$ & $33(24.6 \%)$ & 0.68049 & $0.854 \mid(0.4031-1.8099)$ \\
\hline 03 & $10(18.2 \%)$ & 24 (I7.9\%) & 0.96480 & $1.0185(0.4508-2.3014)$ \\
\hline 04 & $12(21.8 \%)$ & $29(21.6 \%)$ & 0.97867 & $1.0104(0.4723-2.1619)$ \\
\hline 07 & 21 (38.2\%) & 42 (31.3\%) & 0.36499 & $1.3529(0.7027-2.6048)$ \\
\hline 08 & $5(9.1 \%)$ & $22(16.4 \%)$ & 0.19103 & $0.509(0.1824-1.4213)$ \\
\hline 09 & 0 & $4(3.0 \%)$ & 0.24936 & 0 (Undefined) \\
\hline 10 & $4(7.3 \%)$ & $9(6.7 \%)$ & 0.55535 & $1.0893(0.3210-3.6972)$ \\
\hline II & II (20.0\%) & 28 (20.9\%) & 0.89009 & $0.9464(0.4334-2.0667)$ \\
\hline 12 & $2(3.6 \%)$ & $3(2.2 \%)$ & 0.45410 & $1.6478(0.2677-10.144)$ \\
\hline 13 & $15(27.3 \%)$ & $22(16.4 \%)$ & 0.08758 & 1.909 । (0.9027-4.0377) \\
\hline 14 & $4(7.3 \%)$ & $5(3.7 \%)$ & 0.24593 & $2.0235(0.5224-7.8384)$ \\
\hline 15 & $6(10.9 \%)$ & $22(16.4 \%)$ & 0.33287 & $0.6234(0.2379-1.6331)$ \\
\hline 16 & $2(3.6 \%)$ & $12(9.0 \%)$ & 0.16879 & $0.3836(0.0830-1.774 I)$ \\
\hline
\end{tabular}

Abbreviations: $\mathrm{OD}$, odds ratio; $\mathrm{Cl}$, confidence interval.

Table 8 Frequency of HLA-DQBI Allelic Groups in Patients and Controls

\begin{tabular}{|c|c|c|c|c|}
\hline $\begin{array}{l}\text { HLA- } \\
\text { DQB I* }\end{array}$ & $\begin{array}{l}\text { Psoriasis } \\
n=110\end{array}$ & $\begin{array}{c}\text { Controls } \\
n=268\end{array}$ & $p$ & OR (Cl) \\
\hline 02 & $23(4 \mathrm{I} .8 \%)$ & $54(40.3 \%)$ & 0.84685 & $1.0648(0.5629-2.0141)$ \\
\hline 03 & $24(43.6 \%)$ & $62(46.3 \%)$ & 0.43361 & $0.8991(0.4779-1.6913)$ \\
\hline 04 & $4(7.3 \%)$ & 20 (14.9\%) & 0.15121 & $0.447 \mid(0.1454-1.3745)$ \\
\hline 05 & $25(45.5 \%)$ & $55(41.0 \%)$ & 0.57729 & I.I $970(0.6358-2.2533)$ \\
\hline 06 & $20(36.4 \%)$ & $4 \mid(30.6 \%)$ & 0.44116 & $1.2962(0.6693-2.5102)$ \\
\hline
\end{tabular}

Abbreviations: $\mathrm{OD}$, odds ratio; $\mathrm{Cl}$, confidence interval. 
patients, unrelated to the subtype, in Korea. ${ }^{24}$ HLA-DRB1 * 0701 was also present when patients with type II psoriasis were analyzed separately in Taiwan. ${ }^{33}$

The allelic group HLA-B $* 07$ was present more frequently in the control group compared to patients and could be a protective allele, and has not described in the literature as such. HLA-A66, and -Cw2, - $\mathrm{Cw} 4,{ }^{17}$ HLA$\mathrm{A} * 24,-\mathrm{A} * 33$ and $\mathrm{Cw}^{*} 04^{30}$ and $\mathrm{Cw}^{*} 07^{10}$ were previously described as protection antigens.

HLA-B*57 was significantly increased in patients with history of erythrodermic psoriasis, in patients with hospital admissions caused by psoriasis and those with history of psoriasis systemic treatment, compared to the control group. Comparing HLA-B*57 positive patients with negative patients, a difference remains in the ones with history of systemic treatment. Another study ${ }^{34}$ correlated HLA$\mathrm{CW}^{*} 0602$ with clinical parameters. One thousand and nineteen patients from Iceland were typified and, of these, $654(64.2 \%)$ were positive for $\mathrm{Cw} * 0602$. Comparing with $\mathrm{Cw} * 0602$ negative patients, positive patients had an early disease onset, more extensive skin involvement, more frequent relapses due to oropharyngeal infections, or the development of lesions in the sites of trauma. $^{34}$

In patients with psoriatic arthritis, HLA-C*18 was significantly increased compared to the control group. The significant difference was maintained when comparing patients with and without arthritis. HLA-C*18 has not yet been described in the literature as psoriatic arthritis susceptibility. On the other hand, HLA-B*57 has been described as a susceptibility marker, ${ }^{35}$ and, in this study, it remained significantly frequent in this subgroup of patients compared to the control group. Other studies have also highlighted HLA-B17 in association with arthritis. ${ }^{36,37}$ HLA-B17 corresponds to the HLA-B*57 by molecular methods. HLA-B*27 is the most often found in association with psoriatic arthritis ${ }^{38-42}$ and is mostly associated with axial arthritis. ${ }^{7,43-47}$

Schmitt-Egenolf et $\mathrm{al}^{20}$ and Choonhakarn et $\mathrm{al}^{30}$ reported similar haplotype in German and Thai patients with psoriasis: HLA-B57 Cw6 DRB1 * 0701 DQA1 * 0201 DQB1 * 0303, the EH-57.1 haplotype, so named because of the B57 antigen. Kastelan et $\mathrm{al}^{16}$ found a similar haplotype in Croatian patients with psoriasis type I, with a single difference in DQB1: HLA B 57 Cw6 DRB1 * 0701 DQA1 * 0201 DQB1 * 0201. Choonhakam et $\mathrm{al}^{30}$ found two haplotypes, HLA -A*0207 $-\mathrm{B} * 4601-\mathrm{CW}^{*} 01-\mathrm{DRB} 1 * 09-\mathrm{DQB} 1 * 0303$ (EH-46.1) and HLA -A*30 -B*13 -Cw*0602 -DRB1*07 -DQB1*02 (EH-
13.1), the latter similar to that found in Korean patients ${ }^{24}$ (HLA -A*30 -B*13 -Cw*0602 -DRB1*07 -DQA1*02 -DQB1*02), with one difference in DQA1 allele, which has not been typified by Choonhakarn et al. ${ }^{30}$

In the present study, the most frequent haplotype among patients were HLA-A*02 B*57 C*06 DRB1*07 $\mathrm{DQB} 1 * 03$, similar to that described by Schmitt-Egenolf et $\mathrm{al}^{20}$ and Choonhakarn et al. ${ }^{30}$ Another haplotype also found was HLA-A*02 B*13 C*06 DRB1*07 DQB1*02 similar to that found by Tai-Gyu et $\mathrm{al}^{24}$ with one difference, HLA-A*30 allele.

Population and familial studies of antigens and HLA alleles and psoriasis vulgaris show different markers depending on the ethnic origin of the patients. However, it is unclear whether HLA would be a predisposing factor for psoriasis. It is known that the alleles located near a mutation tend to be in linkage disequilibrium with it. ${ }^{48}$ In this case, alleles whose frequency are increased in cohorts of patients could be used to help locate susceptibility genes. In addition, some polymorphic residues in the most common HLA specificities may have the ability to bind and present antigens related to psoriasis, because of the clefts they form in the HLA molecule, determining the size and charge of the binding antigenic peptide. ${ }^{2,433}$ The study of HLA antigens associated with psoriasis may not only indicate the disease susceptibility genes, but also clarify aspects of its pathogenesis. A study in Italy ${ }^{49}$ identified a sequence of four amino acids (Ala 73, Asn 77, Lys 80 and Asp 90) in the binding groove of HLA-Cw $* 0602$ and $\mathrm{Cw}^{*} 04$ in $77,5 \%$ of patients with psoriasis and $50,8 \%$ of controls $(\mathrm{p}=0.0031)$. This sequence was also characteristic in female patients $(80 \%)$ in familial forms $(89.5 \%)$, psoriasis type I (81.8\%) and arthropathic psoriasis $(88.8 \%)$. The nature of the peptide binding grooves varies from one molecule to another, affecting the affinity of binding with endogenous HLA peptides. ${ }^{50}$ The study of the binding of HLA molecules clefts found in patients with psoriasis can contribute to defining the pathogenic peptides that participate in triggering the immune response altered in psoriasis. ${ }^{49}$

\section{Conclusions}

HLA-B*57 and HLA-C*06 were significantly higher in the patients indicating risk for psoriasis. HLA-B $* 57$ was high in patients with history of erythroderma, hospital internment, systemic treatment, and psoriatic arthritis, showing a relation with disease severity. HLA-C*18 was only significantly high in patients with psoriatic arthritis. HLA-B*57, HLA-C*06 and haplotype HLA-A*02B*57C*06DRB1*07 DQB1*03 associated to psoriasis were already described before, and HLA- 
$\mathrm{C}^{*} 18$ was not described in association with psoriasis in other populations.

\section{Acknowledgments}

This study was supported by CNPq and FAPERJ, was approved by the Research Ethics Committee of the University Hospital of the Federal University of Rio de Janeiro, all participants provided informed consent, and this study was conducted in accordance with the Declaration of Helsinki. Parts with interim findings of the whole investigation were presented separately as abstracts and/or posters in the following Dermatology meetings: 67th Meeting of the American Academy of Dermatology - March 2009, San Francisco, CA - USA; 2nd Annual World Psoriasis \& Psoriatic Arthritis Conference - June 2009, Stockholm Sweden; Dermaparty 2009 - Congress of the Slovak Society for Cosmetic and Aesthetic Dermatology - December 2009, Zilina - Slovakia; Grappa - October 2018, Toronto, Canada.

\section{Disclosure}

Dr Flavia de Freire Cassia reports grants from FAPERJ RESEARCH INSTITUTE IN RIO DE JANEIRO, RJ, Brazil and CAPES FOUNDATION - FEDERAL AGENCY/ BRAZIL, during the conduct of the study. The authors report no other potential conflicts of interest for this work.

\section{References}

1. Giardina E, Hüffmeier U, Ravindran J, et al. Tumor necrosis factor promoter polymorphism TNF*-857 is a risk allele for psoriatic arthritis independent of the PSORS1 locus. Arthritis Rheum. 2011;63 (12):3801-3806. doi:10.1002/art.30591

2. Roitberg-Tambour A, Friedman A, Tzfoni EE, et al. Do specific pockets of HLA-C molecules predispose Jewish patients to psoriasis vulgaris? J Am Acad Dermatol. 1994;31:964-968. doi:10.1016/S01909622(94)70265-9

3. Klein J e Sato J, Sato A. The HLA system. NEJM. 2000;343(10):702709. doi:10.1056/NEJM200009073431006

4. Klein J, Sato A, Mackay IR, Rosen FS. The HLA system. Part II. NEJM. 2000;343(11):782-786. doi:10.1056/NEJM200009143431106

5. Russell TJ, Schultes LM, Kuban DJ. Histocompatibility (HL-A) antigens associated with psoriasis. N Engl J Med. 1972;287(15):738-740. doi:10.1056/NEJM197210122871503

6. Ikäheimo I, Silvennoinen-Kassinen S, Karvonen J, Järvinen T, Tiilikainen A. Immunogenetic profile of psoriasis vulgaris: association with haplotypes A2, B13, Cw6, DR7, DQA1*0201 and A1, B17, Cw6, DR7, DQA1*0201. Arch Dermatol Res. 1996;288:63-67. doi:10.1007/ BF02505045

7. Lambert JR, Wright V, Rajah SM, Moll JM. Histocompatibility antigens in psoriatic arthritis. Ann Rheum Dis. 1976;35(6):526-530. doi:10.1136/ard.35.6.526

8. Kastelan M, Gruber F, Cecuk-Jelicic E, Kerhin-Brkljacic V, BrkjacicSurkalovic L, Kastelan A. Analysis of HLA antigens in Croatian patients with psoriasis. Acta Derm Venereol. 2000;Suppl 211:12-13. doi: $10.1080 / 00015550050500040$
9. Lopez-Larrea C, Torre-Alonso JC, Rodriguez-Perez A, Coto E. HLA antigens in psoriatic arthritis subtypes of a Spanish population. Ann Rheum Dis. 1990;49(5):318-319. doi:10.1136/ard.49.5.318

10. Luszczek W, Kubicka W, Cislo M, et al. Strong association of HLACw6 allele with juvenile psoriasis in Polish patients. Immunol Lett. 2002;8:59-64

11. Murray C, Mann DL, Gerber LN, et al. Histocompatibility alloantigens in psoriasis and psoriatic arthritis. Evidence for the influence of multiple genes in the major histocompatibility complex. J Clin Invest. 1980;66(4):670-675. doi:10.1172/JCI109903

12. Atasoy M, Pirim I, Bayrak OF, et al. Association of HLA class I and class II alleles with psoriasis vulgaris in Turkish population. Saudi Med J. 2006;27(3):373-376.

13. Liao HT, Lin KC, Chang YT, et al. Human leukocyte antigen and clinical and demographic characteristics in psoriatic arthritis and psoriasis in Chinese patients. $J$ Rheumatol. 2008;35:891-895.

14. Indhumathi S, Rajappa $\mathrm{M}$, Chandrashekar L, Ananthanarayanan PH, Thappa DM, Negi VS. The HLA-C*06 allele as a possible genetic predisposing factor to psoriasis in South Indian Tamils. Arch Dermatol Res. 2016;308(3):193-199. doi:10.1007/s00403-016-1618-y

15. Hirata J, Hirota T, Ozeki T, et al. Variants at HLA-A, HLA-C, and HLA-DQB1 confer risk of psoriasis vulgaris in Japanese. $J$ Invest Dermatol. 2018;138(3):542-548. doi:10.1016/j.jid.2017.10.001

16. Kastelan M, Gruber F, Cecuk-Jelicic E, Grubic Z, Kastelan A. A new extended haplotype Cw*0602-B57-DRB1*0701-DQA1*0201DQB1*0201 associated with psoriasis in the Croatian population. Exp Dermatol. 2003;28:200-202. doi:10.1046/j.1365-2230.2003.01215.x

17. Kundakçi N, Oskay T, Ölmez Ü, Tutkak H, Gürgey E. Association of psoriasis vulgaris with HLA class I and class II antigens in the Turkish population, according to the age of onset. Int J Dermatol. 2002;41:345-348. doi:10.1111/j.1365-4632.2002.01458.x

18. Cassia FF, Carneiro SC, Marques MT, Pontes LF, Filgueira AL, Porto LC. Psoriasis vulgaris and human leukocyte antigens. J Eur Acad Dermatol Venereol. 2007;21(3):303-310. doi:10.1111/j.1468-3083.2006.02008.x

19. Schmitt-Egenolf M, Boehncke WH, Ständer M, et al. Oligonucleotide typing reveals association of type 1 psoriasis with HLA-DRB $1 * 0701 / 2$, -DQA1*0201, -DQB1*0303 extended haplotype. J Invest Dermatol. 1993;100(6):749-752. doi:10.1111/1523-1747.ep12476080

20. Schmitt-Egenolf M, Eiermann TH, Boehncke WH, et al. Familial juvenile onset psoriasis is associated with the Human Leucocyte Antigen (HLA) class I side of the extended haplotype Cw6- B57DRB1*0701- DQA1*0201- DQB1*0303: a population and family based study. J Invest Dermatol. 1996;106:711-714. doi:10.1111/ 1523-1747.ep12345600

21. Ikäheimo I, Tiilikainen A, Karvonen J, Silvennoinen-Kassinen S. HLA risk haplotype Cw6, DR7, DQA1*0201 and HLA-Cw6 with reference to the clinical picture of psoriasis vulgaris. Arch Dermatol Res. 1996;288(7):363-365. doi:10.1007/BF02507104

22. Enerback C, Martinsson T, Inerot A, et al. Evidence that HLA-Cw6 determines early onset of psoriasis, obtained using sequence-specific iniciadores (PCR-SSP). Acta Derm Venereol. 1997;77(4):273-276.

23. Gonzaga HFS, Torres EA, Alchorne MMA, Gerbase-Delima M. Both psoriasis and benign migratory glossitis are associated with HLA-Cw6. $\mathrm{Br}$ J Dermatol. 1996;135:368-370. doi:10.1046/j.1365-2133.1996.d011006.x

24. Tai-Gyu K, Hye Jung L, Il-Youn J, Tae Yoon K, Hoon H. The association of psoriasis with human leucocyte antigens in Korean population and the influence of age of onset and sex. J Invest Dermatol. 2000;114:309-313. doi:10.1046/j.1523-1747.2000.00863.x

25. Xue-Jun Z, An-Ping Z, Sen Y, et al. Association of HLA class I alleles with psoriasis vulgaris in southeastern Chinese Hans. $J$ Dermatol Sci. 2003;33:1-6. doi:10.1016/S0923-1811(03)00157-9

26. Szczerkowska-Dobosz A, Rebala K, Szczerkowska Z, WitkowskaTobola A. Correlation of HLA-Cw*06 allele frequency with some clinical features of psoriasis vulgaris in the population of northern Poland. J Appl Genet. 2004;45(4):473-476. 
27. Yang S, Ge H-S, Zhang A-P, et al. Haplotype associations of the MHC with psoriasis vulgaris in Chinese Hans. Clin Exp Dermatol. 2004;29:399-405. doi:10.1111/j.1365-2230.2004.01528.x

28. Xue-Jun Z, Shengcai W, Sen Y, et al. HLA-DQA1 and DQB1 alleles are associated with genetic susceptibility to psoriasis vulgaris in Chinese Han. Int J Dermatol. 2004;43:181-187. doi:10.1111/j.13654632.2004.02098.x

29. Oostveen AM, Bergboer JG, van de Kerkhof PC, et al. Genotypephenotype correlations in a prospective cohort study of paediatric plaque psoriasis: lack of correlation between HLA-C*06 and family history of psoriasis. Acta Derm Venereol. 2014;94(6):667-671. doi: $10.2340 / 00015555-1810$

30. Choonhakarn C, Romphruk A, Puapairoj C, et al. Haplotype associations of the major histocompatibility complex with psoriasis in Northeastern Thais. Int J Dermatol. 2002;41:330-334. doi:10.1046/ j.1365-4362.2002.01496.x

31. Vejbaesya S, Eiermann TH, Suthipinititharm P, et al. Serological and molecular analysis of HLA class I and II alleles in Thai patients with psoriasis vulgaris. Tissue Antigens. 1998;52(4):389-392. doi:10.1111/ j.1399-0039.1998.tb03061.x

32. Cardoso CB, Uthida-Tanaka AM, Magalhães RF, Magna LA, Kraemer MHS. Association between psoriasis vulgaris and $\mathrm{MHC}$ DRB, DQB genes as a contribution to disease diagnosis. Eur $J$ Dermatol. 2005;15(3):159-163.

33. Shiou-Hwa J, Tsen-Fang T, Wei-Ling T, Shwu-Huey L, Chun-Hsaing C, Chung-Yi H. HLA-DRB1*0701 and DRB1*1401 are associated with genetic susceptibility to psoriasis vulgaris in a Taiwanese population. $\mathrm{Br} J$ Dermatol. 1998;139:978-983. doi:10.1046/j.13652133.1998.02552.x

34. Gudjonsson JE, Karason A, Runarsdottir EH, et al. Distinct clinical differences between HLA-CW*0602 positive and negative psoriasis patients - an analysis of 1019 HLA-C and HLA-B typed patients. $J$ Invest Dermatol. 2006;106:740-745. doi:10.1038/sj.jid.5700118

35. Beaulieu AD, Roy R, Mathon G, et al. Psoriathic arthritis: risk factors for patients with psoriasis - a study based on histocompatibility antigen frequencies. $J$ Rheumatol. 1983;10(4):633-636.

36. Karvonen J, Lassus A, Sievers U, Tiilikainen A. HL-A antigens in psoriatic arthritis. Ann Clin Res. 1974;6(5):304-307.

37. Fournie B, Granel J, Heraud A, et al. HLA-B and psoriatic rheumatism. Study of 193 cases. Rev Rhum Mal Osteoartic. 1991;58(4):269273.

38. Zachariae H, Hjortshooj A, Kissmeyer-Nielsen F, Svejgaard A, Svejgaard E, Zachariae E. HL-A antigens and psoriatic arthritis. Acta Dermatol Venereol. 1974;54(6):443-447.
39. Marcusson J, Moller E, Thyresson N. HLA antigens (17,27, UPS) in psoriasis with special reference to patients with arthritic lesions. Acta Dermatol Venerol. 1975;55:297-300.

40. Armstrong RD, Panavi GS, Welsh KI. Histocompatibility antigens in psoriasis, psoriatic arthropathy and ankylosing spondilitis. Ann Rheum Dis. 1983;42(2):142-146. doi:10.1136/ard.42.2.142

41. McHugh NJ, Laurent MR, Treadwell BL, Tweed JM, Dagger J. Psoriatic arthritis: clinical subgroups and histocompatibility antigens. Ann Rheum Dis. 1987;46(3):184-188. doi:10.1136/ard.46.3.184

42. Gonzalez S, Garcia-Fernandez S, Martinez-Borra J, et al. High variability of HLA-B27 alleles in ankylosing spondylitis and related spondyloarthropaties in the population of northern Spain. Hum Immunol. 2002;63(8):673-676.

43. Karvonen J. HL-A antigens in psoriasis with special reference to the clinical type, age of onset, exarcebations after respiratory infections and occurrence of arthritis. Ann Clin Res. 1975;7(5):301-311.

44. Roux H, Mercier P, Maestracci D, et al. Psoriatic arthritis and HLA antigens. J Rheumatol. 1977;4:64-65.

45. Eastmond CJ, Woodrow JC. The HLA system and the arthropathies associated with psoriasis. Ann Rheum Dis. 1977;36(2):112-120. doi:10.1136/ard.36.2.112

46. Queiro-Silva R, Torre-Alonso JC, Tinture-Eguren T, Lopez-Lagunas I. The effect of HLA-DR antigens on the susceptibility to, and clinical expression of psoriatic arthritis. Scand $J$ Rheumatol. 2004;33(5):318-322. doi:10.1080/03009740410005953

47. Bonfiglioli R, Bértolo MB, Sampaio-Barros PD, et al. Características da artrite psoriásica nos serviços de reumatologia da FCMUNICAMP e HMCP-PUCCAMP. Rev Bras Reumatol. 2006;46(2): S135.

48. Capon F, Munro M, Barker J, Trembath R. Searching for the major histocompatibility complex psoriasis susceptibility gene. $J$ Invest Dermatol. 2002;118:745-751. doi:10.1046/j.1523-1747.2002.01749.x

49. Brazzelli V, Quaglini M, Martinetti M, et al. A peculiar sequence motif in the alpha-1-domain of the HLA-C molecule in psoriasis. Dermatology. 2000;200:99-103. doi:10.1159/000018338

50. Matsumura M, Fremont DH, Peterson PA, Wilson IA. Emerging principles for the recognition of peptide antigens by MHC class I molecules. Science. 1992;257(5072):927-934. doi:10.1126/ science. 1323878

\section{Publish your work in this journal}

Psoriasis: Targets and Therapy is international, peer-reviewed, open access journal focusing on psoriasis, nail psoriasis, psoriatic arthritis and related conditions, identification of therapeutic targets and the optimal use of integrated treatment interventions to achieve improved outcomes and quality of life. Visit http://www.dovepress. com/testimonials.php to read real quotes from published authors. 